\title{
Endothelial Dysfunction in Insulin-Resistant Rats is Associated with Oxidative Stress and COX Pathway Dysregulation
}

\author{
A. OUDOT ${ }^{1}$, D. BEHR-ROUSSEL ${ }^{1}$, S. COMPAGNIE ${ }^{1}$, S. CAISEY ${ }^{1}$, O. LE COZ $^{1}$, \\ D. GORNY ${ }^{1}$, L. ALEXANDRE ${ }^{1}$, F. GIULIANO ${ }^{1,2}$ \\ ${ }^{1}$ Pelvipharm, Orsay, ${ }^{2}$ AP-HP, Neuro-Uro-Andrology Unit, Department of Physical Medicine and \\ Rehabilitation, Raymond Poincaré Hospital, Garches, France
}

Received April 22, 2008

Accepted June 27, 2008

On-line July 25, 2008

\section{Summary}

Because insulin resistance is inevitably associated with cardiovascular complications, there is a need to further investigate the potential involvement of oxidative stress and the cyclo-oxygenase (COX) pathway in the vascular modifications associated to this pathological context. Endothelial function was evaluated in control and fructose-fed rats (FFR) by i) in vitro study of endothelium-dependent and -independent relaxations of aortic rings, and ii) in vivo telemetric evaluation of pressor response to norepinephrine. After 9 weeks of diet, FFR displayed hypertriglyceridemia, hyperinsulinemia and exaggerated response to glucose overload. Aortic rings from control rats and FFR exhibited comparable endothelium-dependent relaxations to Ach. In the presence of indomethacin, relaxations were significantly reduced. FFR showed exaggerated pressor responses to norepinephrine that were abolished with indomethacin. Urinary nitrites/nitrates, 8-isoprostanes and thromboxane $B_{2}$ excretion levels were markedly enhanced in FFR, whereas the plasma levels of 6-keto prostaglandin $F_{1 \alpha}$ were unchanged. In conclusion, fructose overload in rats induced hypertriglyceridemia and insulin resistance associated with an enhanced oxidative stress. This was associated with COX pathway dysregulation which could be one of the contributors to subsequent vascular dysfunction. Consequently, reduction of oxidative stress and regulation of the COX pathway could represent new potential therapeutic strategies to limit vascular dysfunction and subsequent cardiovascular complications associated with insulin resistance.

\section{Key words}

Endothelial dysfunction - Insulin resistance • Oxidative stress • Cyclo-oxygenase

\section{Corresponding author}

F. Giuliano, AP-HP, Neuro-Uro-Andrology Unit, Department of Physical Medicine and Rehabilitation, Raymond Poincaré Hospital, 104 bd Raymond Poincaré, 92380 Garches, France. Fax: +33147107615. E-mail: giuliano@cyber-sante.org

\section{Introduction}

Insulin resistance is typically defined by the reduced sensitivity to insulin actions that regulate glucose disposal, and results ultimately in type 2 diabetes mellitus. In patients with insulin resistance such as in the metabolic syndrome, cardiovascular risk is markedly increased (Grundy 2006). However, causes and consequences of insulin resistance on cardiovascular complications are yet to be explored in order to limit the cascade of sequelae and co-morbid disease (Haffner 1999).

Endothelium appears to play a key role in the vascular damages induced by insulin resistance associated with metabolic syndrome (Kim et al. 2006). Patients with metabolic syndrome or type 2 diabetes mellitus exhibit impaired endothelium-dependent vasodilation (Baron 1999). It is now recognized that these disturbances in endothelial function are principal players in the ischemic manifestations of coronary artery disease (Anderson et al. 1995, Meredith et al. 1993). In fact, endothelial dysfunction has been suggested to precede the elevation of blood pressure (Katakam et al. 1998) and contribute to the development of cardiovascular diseases in insulin resistance (Shinozaki et 
al. 1995) and may therefore represent both a surrogate marker for cardiovascular risk as well as a relevant therapeutic target.

Oxidative stress has been suggested to i) contribute to insulin resistance (Carantoni et al. 1998, Gopaul et al. 2001), and (ii) play a crucial role in the pathogenesis of endothelial dysfunction(Esper et al. 2006, Sonnenberg et al. 2004). The most important consequence of increased oxidative stress on vascular endothelial function is the decrease in NO bioavailability resulting from both $\mathrm{NO}$ inactivation by superoxide anions and NO synthase uncoupling (Griendling and Alexander 1997). An increase in free radical production could also activate the cyclo-oxygenase (COX) pathway resulting in an imbalance between vasoconstrictor and vasodilator prostanoid synthesis. Indeed, it was suggested that both hyperglycemia (Cosentino et al. 2003) and oxidative stress dysfunction (Bachschmid et al. 2005, Cosentino et al. 2003) were associated with an increase in vasoconstrictor thromboxane $\mathrm{A}_{2}$ and a decrease in vasodilator prostacyclin $\left(\mathrm{PGI}_{2}\right)$ produced by COX. Thus, this modulation of the prostanoid production could result in endothelial dysfunction (Bachschmid et al. 2005, Cosentino et al. 2003).

We aimed to investigate new potential mechanisms linking disrupted glucose metabolism to subsequent cardiovascular complications by studying endothelial function and the potential involvement of oxidative stress and the COX pathway in the vascular modifications induced by insulin resistance. Since fructose consumption might be a contributing factor to the development of metabolic abnormalities observed in the metabolic syndrome (Bray et al. 2004, Elliott et al. 2002), we used the fructose-fed rat (FFR) as a model of insulin resistance. Endothelial function was evaluated both in vitro and in vivo by 1) the study of endotheliumdependent relaxations by isometric tension studies on aortic rings, and 2) telemetric evaluation of arterial pressure and pressor responses to norepinephrine in conscious unrestrained rats. We also sought to determine the effects of fructose overload on biochemical indicators of the extent of oxidative stress, and COX pathway dysregulation in FFR.

\section{Methods}

\section{Experimental design}

After one week acclimatization period, male Wistar rats (Charles River, France, 180-220 g) were randomly placed on a purified control chow (Control: TD.03102) or on an isocaloric fructose-enriched diet (fructose-fed rats or FFR: TD.89247 containing 18.3\% protein, $60.3 \%$ fructose and $5.2 \%$ lard) (Teklad Labs, Madison, WI, USA) for the following 9 weeks. All procedures were performed in accordance with the legislation on the use of laboratory animals (NIH publication $\mathrm{N}^{\circ} 85-23$, revised 1996) and Animal Care Regulations in force in France as of 1988.

After 9 weeks of diet, in vitro vascular reactivity was evaluated in a first set of animals (Control: $n=12$, FFR: $n=12$ ). In this set of rats, 24-hour urine and blood samples were collected for biochemical determinations.

In a second set of animals (Control: $n=10$, FFR: $\mathrm{n}=10$ ), blood pressure and pressor responses to norepinephrine were investigated and oral glucose tolerance tests (OGTT) were performed in a subset of animals from this series (Control: $n=8, F F R$ : $n=8$ ) after 9 weeks of diet.

A third set of animals (Control: $n=8$, FFR: $n=8$ ) was carried out to investigate the role of COX pathway in pressor responses to norepinephrine following indomethacin injection after 9 weeks of fructose-enriched diet.

\section{In vitro vascular reactivity}

Rats were deeply anesthetized with urethane (1.2 g/kg, i.p.). Aortic rings were obtained and placed in organ chambers $(5 \mathrm{ml})$ filled with an oxygenated physiological salt solution (PSS: $\mathrm{NaCl} 118.0 ; \mathrm{KCl} 4.6$; $\mathrm{CaCl}_{2}$ 2.5; $\mathrm{KH}_{2} \mathrm{PO}_{4} 1.2 ; \mathrm{MgSO}_{4} 1.2 ; \mathrm{NaHCO}_{3} 25.0$ and glucose $11.1 \mathrm{mM}$ ) at $37{ }^{\circ} \mathrm{C}$ for isometric tension recording. After equilibration the preparations were precontracted by phenylephrine $\left(10^{-6} \mathrm{M}\right)$. Concentrationresponse curves to endothelium-dependent relaxant agonist (i.e. acetylcholine, ACh, $10^{-10}$ to $10^{-5} \mathrm{M}$ ) were performed in presence or absence of indomethacin $\left(10^{-5} \mathrm{M}\right)$. Every $2 \mathrm{~min}$, increasing doses of Ach were added to the organ bath. Since aortic relaxant responses to Ach were stable, relaxations were recorded during the last $20 \mathrm{~s}$ before adding a new dose. Indomethacin was added to the organ bath $30 \mathrm{~min}$ before precontraction to phenylephrine preceding concentration-response curves.

To evaluate endothelium-independent relaxations, concentration-response curves to sodium nitroprusside (SNP, $10^{-10}$ to $10^{-6} \mathrm{M}$ ) were performed. For each concentration-response curve, a $\mathrm{pD} 2$ value $\left(-\log \left[\mathrm{EC}_{50}\right]\right.$ where $\mathrm{EC}_{50}$ was the concentration of drug that produced $50 \%$ of the maximum effect) and a 
maximal effect value ( $E_{\max }$, maximum response) were determined.

\section{In vivo telemetric measurement of blood pressure}

Before the end of the 8th week of treatment period, rats were anesthetized ( $2 \%$ inhaled isoflurane), and each animal was implanted with a radio-telemetry transmitter (model PA-C40, Data Sciences International, St. Paul, MN, USA). The catheter was introduced into the femoral artery and advanced to the abdominal aorta. The right jugular vein was catheterized to allow subsequent intravenous perfusion. After surgery, each rat was allowed to recover for at least 7 days before blood pressure measurement. Telemetric measurements in conscious unrestrained rats were performed at the end of the treatment period (week 9). Briefly, after $30 \mathrm{~min}$ acclimatization blood pressure was recorded for $30 \mathrm{~min}$ (baseline parameters measured during the last $5 \mathrm{~min}$ ). Subsequently, increasing doses of norepinephrine were infused i.v. for $5 \mathrm{~min}$ each $(50,100,200,400 \mathrm{ng} / \mathrm{kg} / \mathrm{min})$. Pressor responses were determined for each dose as an average of the recorded response during the final minute. In the third set of animals, to investigate the role of COX pathway in pressor responses to norepinephrine, indomethacin $(7.5 \mathrm{mg} / \mathrm{kg}$ ) (Ruiz et al. 1994) or its vehicle was intravenously injected $30 \mathrm{~min}$ before the beginning of the norepinephrine perfusion.

\section{Evaluation of glucose metabolism}

After telemetric BP measurements, rats were fasted overnight, then gavaged with a solution of glucose $1 \mathrm{~g} / \mathrm{kg}$ and anesthetized with isoflurane. Blood samples were taken from the tail vein at $0,10,20,30,60$ and 90 minutes after the gavage. Fasting levels of glycemia and insulinemia were determined at time 0 . Blood glucose was determined immediately after collection (Accu-chek active, Roche diagnostics, France), insulin concentration was determined in plasma samples by enzyme immunoassay (Cayman Chemical, MI, USA). The insulin sensitivity index (ISI) was calculated using the formula of Matsuda and DeFronzo (1999) as follows:

ISI $=10000 / \sqrt{ }[($ FPG $\times$ FPI $) \times($ mean OGTT glucose concentration $\mathrm{x}$ mean OGTT insulin concentration)],

FPG being fasting plasma glucose (in mg/dl), FPI fasting plasma insulin $(\mu \mathrm{U} / \mathrm{ml})$ and mean OGTT (oral glucose tolerance test) glucose and insulin concentration being obtained from the area under the curve of glucose or insulin concentration evolution during the $90 \mathrm{~min}$ following oral gavage with $1 \mathrm{~g} / \mathrm{kg}$ glucose solution.

\section{Biochemical determinations}

At the end of the 9th week of diet, rats to be included in in vitro vascular reactivity studies were fasted overnight and placed in metabolic cages to collect 24-h urine samples, and plasma samples were also collected. Plasma and urinary creatinine was determined by spectrophotometry (Jaffe 1886). The urinary concentration of nitrates and nitrites, 8-isoprostanes and thromboxane $\mathrm{B}_{2}$, and plasma 6-keto prostaglandin F1 $\alpha$ were determined using commercially available assay kits (Cayman Chemical, MI, USA). Plasma triglycerides were measured using a colorimetric method (Sigma assay kit, St Louis, MO, USA). All urine concentrations were corrected by the clearance of creatinine to limit variability in the assays due to changes in renal excretory function (Behr-Roussel et al. 2000).

\section{Statistical analysis}

All data were expressed as mean \pm S.E.M. Most of the results were analyzed using Student's t-test. In vitro vascular relaxation responses curves and pressor responses to norepinephrine results were analyzed using a two-way ANOVA statistical analysis followed by Bonferroni's complementary analysis when relevant. For pD2 and $E_{\max }$ values, statistical analysis was performed according to the extra sum of squares $F$ test principle with GraphPad Prism ${ }^{\circledR} 4.03$ software. $\mathrm{P}<0.05$ values were considered significant.

\section{Results}

\section{Metabolic parameters}

After 9 weeks of control or fructose-enriched diet, body weights were similar in both control and FFR rats (Table 1).

Although fasting glycemia was not significantly changed by 9 weeks of fructose overload, insulinemia was significantly increased in FFR compared to control rats (Table $1, \mathrm{P}=0.036$ ). Moreover, oral glucose tolerance test revealed significant differences in the increase of plasma glucose and insulin levels. Indeed, in response to oral administration of $1 \mathrm{~g} / \mathrm{kg}$ glucose, FFR displayed a decreased insulin sensitivity index compared to control rats (Table $1, \mathrm{P}=0.014$ ) indicating insulin resistance in these animals.

Mean arterial pressure (MAP) and heart rate, 
Table 1. Metabolic parameters in control and FFR after 9 weeks of fructose-enriched diet.

\begin{tabular}{|c|c|c|c|}
\hline & Control & FFR & $\mathbf{P}=$ \\
\hline \multicolumn{4}{|l|}{ Obesity } \\
\hline Body weight (g) & $419 \pm 9$ & $408 \pm 12$ & NS \\
\hline \multicolumn{4}{|l|}{ Glucose metabolism } \\
\hline Fasting glycemia (mg/dl) & $113.4 \pm 11.8$ & $134.7 \pm 5.8$ & NS \\
\hline Fasting insulinemia $(\mathrm{ng} / \mathrm{ml})$ & $1.26 \pm 0.25$ & $2.34 \pm 0.38^{*}$ & 0.036 \\
\hline Insulin sensitivity index & $2.17 \pm 0.29$ & $1.25 \pm 0.13^{*}$ & 0.014 \\
\hline \multicolumn{4}{|l|}{ Baseline blood pressure } \\
\hline Mean arterial pressure $(\mathrm{mmHg})$ & $106.5 \pm 4.5$ & $103.2 \pm 5.6$ & NS \\
\hline Heart rate (beats/min) & $407 \pm 19$ & $380 \pm 9$ & NS \\
\hline \multicolumn{4}{|l|}{ Lipids } \\
\hline Plasma triglycerides (mM) & $1.28 \pm 0.15$ & $2.19 \pm 0.28 * *$ & 0.009 \\
\hline
\end{tabular}

Values are expressed as means \pm S.E.M. Student's t-test, NS: not significant, $* P<0.05, * * P<0.01$.

measured telemetrically in conscious animals after a 30-min acclimation period were unchanged after 9 weeks of fructose-enriched diet (Table 1).

Finally, FFR were highly hypertriglyceridemic compared to the control rats (Table 1).

\section{In vitro vascular reactivity}

Precontractions tensions elicited by $10^{-6} \mathrm{M}$ phenylephrine were similar in aortic rings from control and FFR, irrespective of the experimental conditions before ACh-dependent relaxation: $572 \pm 66 \mathrm{mg} / \mathrm{g}$ wet weight in control vs. $440 \pm 63 \mathrm{mg} / \mathrm{g}$ wet weight in FFR $(\mathrm{P}=0.17)$, before ACh-dependent relaxation in the presence of indomethacin: $402 \pm 47 \mathrm{mg} / \mathrm{g}$ wet weight in control vs. $320 \pm 40 \mathrm{mg} / \mathrm{g}$ wet weight in FFR ( $\mathrm{P}=0.20$ ), and before SNP-dependent relaxation: $675 \pm 99 \mathrm{mg} / \mathrm{g}$ wet weight in control vs. $640 \pm 110 \mathrm{mg} / \mathrm{g}$ wet weight in FFR $(\mathrm{P}=0.82)$. Aortic rings from control rats and FFR exhibited comparable endothelium-dependent relaxations to Ach (Fig. 1A) with unchanged pD2 (7.65 \pm 0.05 in control rats vs. $7.83 \pm 0.08$ in FFR, NS) and $\mathrm{E}_{\max }(-99.1 \pm$ $1.7 \%$ in control rats vs. $-95.2 \pm 1.08 \%$ in FFR, NS). However, when indomethacin was added to the organ bath, a significant reduction of endothelium-dependent relaxations to ACh was observed in aortas from FFR compared to control rats $(\mathrm{P}<0.001$ Two-way ANOVA) (Fig. 1B), which is associated with a reduction of Emax $(-104.0 \pm 1.9 \%$ in control rats vs. $-90.7 \pm 3.1 \%$ in FFR, $\mathrm{P}<0.01)$ and unchanged $\mathrm{pD} 2(7.79 \pm 0.07$ in control rats vs. $7.70 \pm 0.12$ in FFR, NS). Conversely, aortic endothelium-independent relaxations to SNP were increased in the aortas from FFR compared to control rats (Fig. 1C).

In vivo telemetric measurement of pressor response to norepinephrine

During the first $30 \mathrm{~min}$ of baseline recording, the pressure was stable in control rats and FFR. The infusion of increasing concentrations of norepinephrine elicited a dose-dependent increase in arterial pressure (Fig. 2) with both an elevation of systolic and diastolic BP (data not shown). The response to norepinephrine was clearly enhanced in FFR compared to control rats $(\mathrm{P}<0.01$ Two-way ANOVA, Fig. 2A).

The administration of indomethacin $30 \mathrm{~min}$ before the beginning of norepinephrine infusion significantly reduced the amplitude of the pressor response to norepinephrine in both controls (Fig. 2B) and FFR (Fig. 2C). However, the downward shift of the pressor response curve following indomethacin administration was more important in FFR than in control rats. Indeed, when indomethacin was intravenously injected, the pressor responses to norepinephrine in FFR (Fig. 2A) were normalized and not significantly different from control rats ( $>0.05$ Two-way ANOVA, Fig. 2D) except during the $400 \mathrm{ng} / \mathrm{kg} / \mathrm{min}$ norepinephrine perfusion.

Biochemical evaluation of oxidative stress and cyclooxygenase products

Both plasma and urine creatinine levels were similar in control and FFR, resulting in a preserved creatinine clearance following 9 weeks of fructose- 
A.

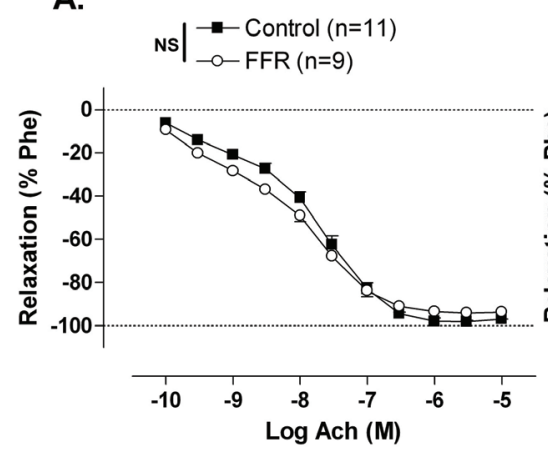

B.

$* * *-\operatorname{Control}(n=11)$

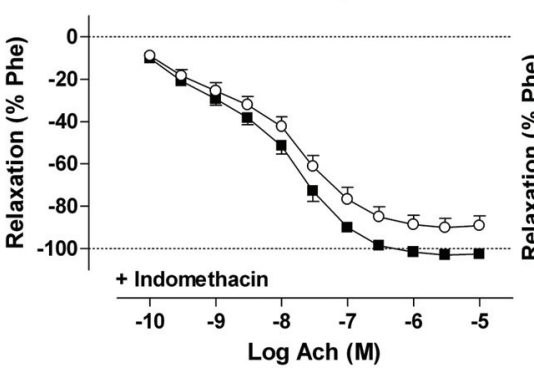

c.
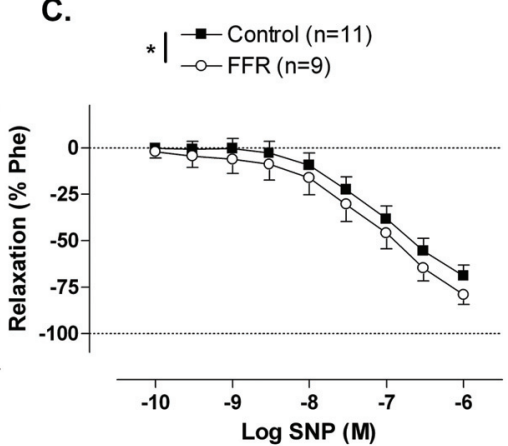

Fig. 1. Comparison of endothelium-dependent $(A, B)$ and -independent $(C)$ relaxations obtained in in vitro experiments with aortic rings in absence $(A, C)$ or in presence $(B)$ of $10 \mu \mathrm{M}$ indomethacin. Two-way ANOVA: NS: not significant, $* P<0.05, * * * P<0.001$.

A.

$$
* * \begin{aligned}
& \rightarrow-\operatorname{Control}(n=8) \\
& -\operatorname{O-FFR}(n=6)
\end{aligned}
$$

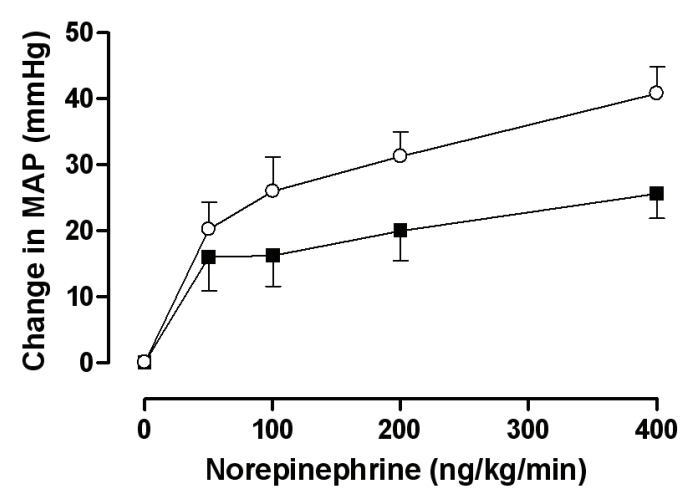

B.

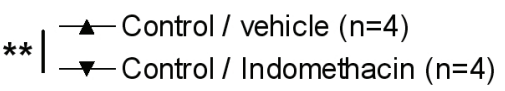

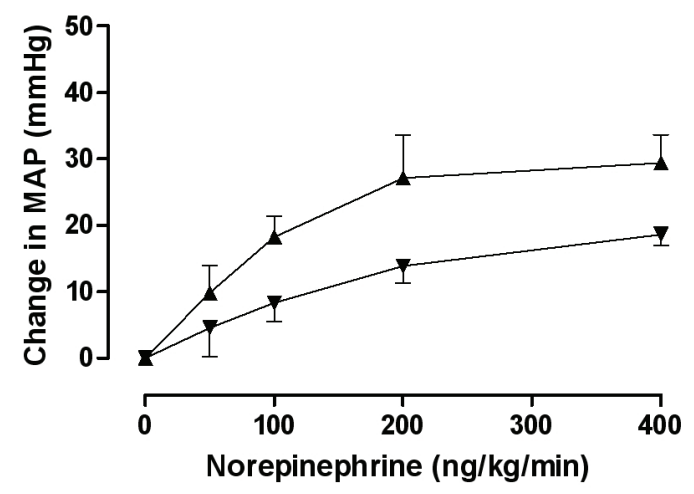

C. $* * * \mid \begin{aligned} & \sim-F F R / \text { vehicle }(n=3) \\ & \longrightarrow-F F R / \text { Indomethacin }(n=4)\end{aligned}$

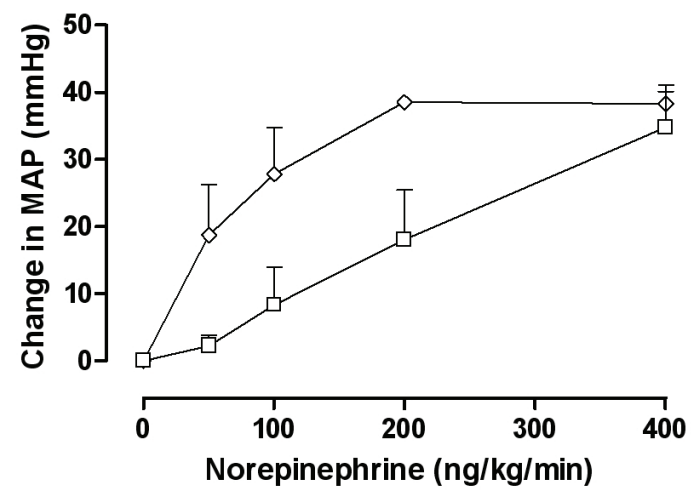

D. ns $\underset{-\longrightarrow F F R / \text { Indomethacin }(n=4)}{\longrightarrow-\text { Control / Indomethacin }(\mathrm{n}=4)}$

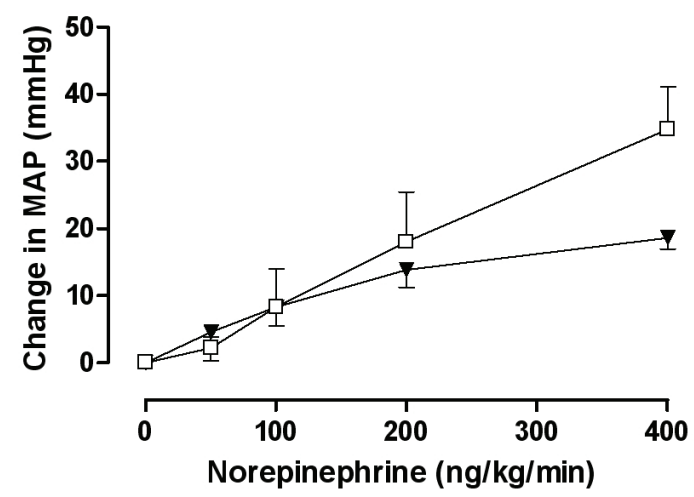

Fig. 2. Concentration response curves to increasing doses of norepinephrine infusion on mean arterial pressure (MAP) measured in vivo in conscious animals (control and FFR) at the end of the treatment period (week 9) (A) or, 30 min after intravenous vehicle or indomethacin $7.5 \mathrm{mg} / \mathrm{kg}$ injection (B, C, D). Two-way ANOVA: NS: not significant, $* * P<0.01, * * * P<0.001$.

enriched diet $(0.49 \pm 0.05$ in control vs. $0.39 \pm 0.05$ in FFR $\mathrm{ml} / \mathrm{min} ; \mathrm{P}=0.16)$.

Both urinary nitrites/nitrates $(\mathrm{P}<0.05)$ and 8 -isoprostanes $(\mathrm{P}<0.01)$ levels were markedly increased in FFR compared to control animals (Fig. 3A). Whereas urinary thromboxane $\mathrm{B}_{2}$ excretion was greatly enhanced in the FFR $(\mathrm{P}<0.05)$ as a result of the fructose-enriched diet, the levels of the stable metabolite of prostacyclin $\left(\mathrm{PGI}_{2}\right)$, 6-keto prostaglandin $\mathrm{F}_{1 \alpha}$ were similar in control and FFR rats (Fig. 3B). 
A.

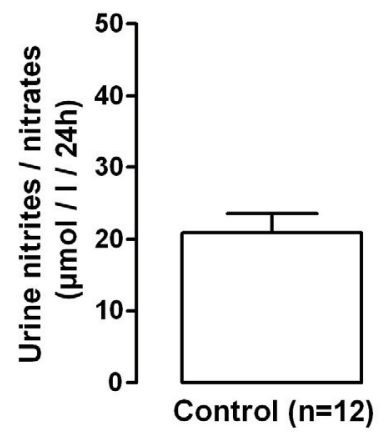

B.

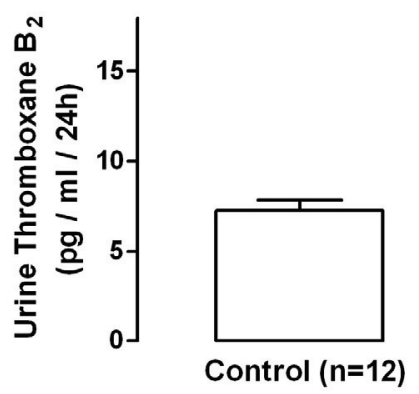

Oxidative stress

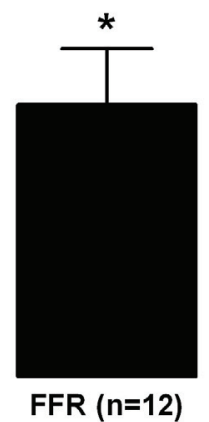

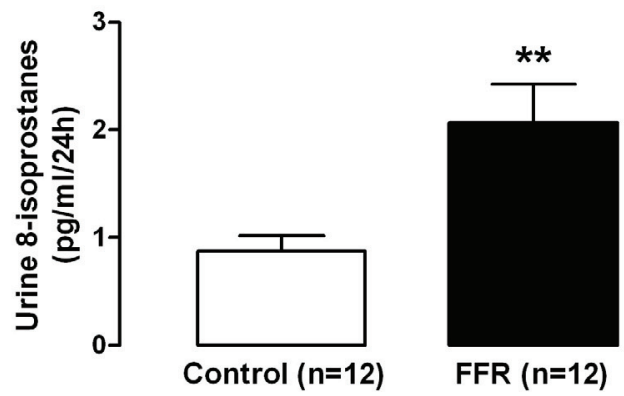

coX products
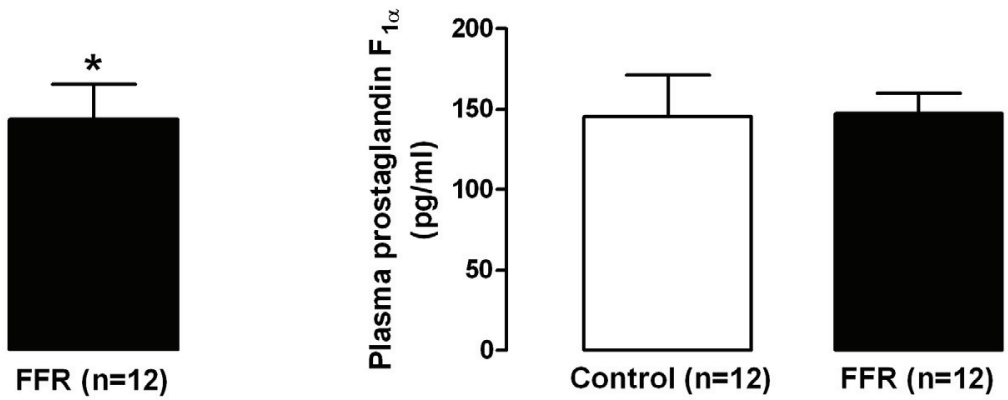

Fig. 3. Levels of oxidative stress markers (nitrites/nitrates, 8-isoprostanes) (A), and COX products (thromboxane $B_{2}$ and prostaglandin $\left.\mathrm{F}_{1} \mathrm{a}\right)(\mathrm{B})$ in control and FFR after 9 weeks of treatment. Student's t-test, NS: not significant, $* \mathrm{P}<0.05, * * \mathrm{P}<0.01$.

\section{Discussion}

In the present study, feeding of rats with fructose-enriched diet for 9 weeks induced hyperinsulinemia, impaired glucose tolerance and hypertriglyceridemia with no change in blood pressure. Many other studies using the FFR have also reported an increased fasting plasma insulin and/or exaggerated response to glucose overload (Lee et al. 2006, Nagai et al. 2002, Nakagawa et al. 2006, Vasudevan et al. 2005) as well as a consistent hypertriglyceridemia in accordance with our results (Bartus et al. 2005, Nagai et al. 2002, Nakagawa et al. 2006, Nyby et al. 2005, Sanchez-Lozada et al. 2007, Shinozaki et al. 2000, Takagawa et al. 2002). Interestingly, insulin levels and high triglyceridemia are known to enhance free radical production (Bakker et al. 2000, Kim et al. 2006). Oxidative stress has been evaluated by the measure of the clinically validated biomarker: urinary 8-isoprostanes (Montuschi et al. 2004). We have confirmed the excessive non-enzymatic in vivo lipid peroxidation as a result of oxidative stress. In agreement with the present observation, oxidative stress has repeatedly been evidenced in FFR (Delbosc et al.
2005, Miatello et al. 2005, Nyby et al. 2005, Shinozaki et al. 2000). This may directly result from elevated glycemia and triglyceridemia present in these rats.

In contrast, a somewhat surprising finding of this study is the fact that 9 weeks of fructose-enriched diet did not modify baseline blood pressure and heart rate. These results are in contradiction with several studies reporting that FFR are hypertensive (Kamide et al. 2002, Miatello et al. 2005, Nagai et al. 2002, Nyby et al. 2005, SanchezLozada et al. 2007, Takada et al. 2001). In these studies, BP has been measured by tail-cuff plethysmography. In contrast, using telemetry, D'Angelo et al. (2005) reported that 8 weeks of fructose feeding ( $66 \%$ fructose, $12 \%$ lard) produced no change in baseline MAP in agreement with our data. We believe that tail-cuff BP results must be cautiously interpreted since it may yield misleading results due to the restraint and thermal stress imposed to the animal. These challenging conditions may indeed provide $\mathrm{BP}$ measurements that may be better compared to a pressor response rather than a baseline BP (Pelaez et al. 2003).

Fructose-enriched diet associated with moderate amounts of fat (Reed et al. 1994) induced insulin resistance associated with hyperlipidemia in accordance 
with previously reported results (Galipeau et al. 2001, Miatello et al. 2002, Song et al. 2004) with no change in blood pressure. This depicts some of the abnormalities associated with an early stage of the metabolic syndrome development. Moreover, a direct consequence of these abnormalities (insulin resistance and hyperlipidemia) may be an enhanced oxidative stress which could constitute the starting point for cardiovascular complications associated with the metabolic syndrome.

In addition to its essential metabolic actions, insulin binding to its receptors has been demonstrated to stimulate the production of $\mathrm{NO}$ at the endothelial level (Baron and Clark 1997). Since NO constitutes one of the major vasodilator mediator, the defect in insulin signaling pathway caused by insulin resistance appears to be closely associated with endothelial dysfunction. Interestingly, endothelium-dependent reactivity of isolated aortic rings from FFR did not seem to be affected. However, in the presence of indomethacin, marked endothelial dysfunction was revealed. These results suggest that, in FFR, the net balance between vasodilator and vasoconstrictor mechanisms does not appear to be modified. However, the contribution of each independent pathway seems to be modified, suggesting that compensatory relaxation mechanisms are still able to buffer specific dysfunctions of vasodilator or vasoconstrictor pathways already present at a very early stage of the metabolic syndrome. Such compensatory mechanisms have been previously demonstrated in SHR in which up-regulation of endothelium-independent vasodilation partly balanced endothelial dysfunction (Behr-Roussel et al. 2003). Interestingly, as we demonstrated in the present work, the same observation seems to hold true in FFR since endotheliumindependent relaxing mechanisms were upregulated.

Next, we could closely examine the modulation of the endothelium-dependent vasodilation pathways in aortas from FFR (i.e. NO and COX products). The most likely event occurring in FFR to explain the alteration of endothelium-dependent relaxations is the impairment of the NO pathway. In fact, insulin binding to its receptors has been demonstrated to stimulate the production of NO from the endothelium. Moreover, in FFR, insulin resistance seems to be mediated via a decreased insulin receptor expression (Catena et al. 2003). Although no direct measurement of impaired NO production was performed in the present study, several elements suggest that NO bioavailability is disturbed in FFR. We have evidenced an increase in oxidative stress by elevated levels of 8-isoprostanes. The elevation of reactive oxygen species production observed in FFR could reduce NO bioavailability by inactivating $\mathrm{NO}$ to peroxynitrite. In this respect, the elevation of urinary nitrites/nitrates in FFR might indeed reflect the impaired NO bioavailability since peroxynitrite, as well as NO, is metabolized in nitrites and nitrates (Dedon and Tannenbaum 2004). Several studies reported a decreased vascular eNOS expression and/or activity in FFR (Miatello et al. 2005, Nyby et al. 2005, Shinozaki et al. 1999, Shinozaki et al. 2000) while Shinozaki et al. (1999) showed eNOS uncoupling in FFR. Taken together, all these data are strongly in favor of a decreased NO bioavailability that could explain the impaired vascular endotheliumdependent relaxation in FFR.

COX products are also critical regulators of vascular tone (Davidge 2001). In the present study, since COX inhibition revealed endothelial dysfunction in FFR, it is suggested that an increased production of endothelium-dependent vasodilator COX products occurred in FFR (i.e. $\mathrm{PGI}_{2}$ or $\mathrm{PGE}_{2}$ ). Yet, basal circulating levels of the stable metabolite of $\mathrm{PGI}_{2}$, 6-ketoprostaglandin $F_{1 \alpha}$, were not modified in FFR which is in accordance with previous studies (Bartus et al. 2005). However, it must be kept in mind that our results were obtained in unstimulated conditions and this might not preclude a compensatory increased production of $\mathrm{PGI}_{2}$ in response to a vasodilator stimulus. Vasodilator prostaglandin $E_{2}$ may also be upregulated in FFR but this possibility was not assessed and remains to be investigated.

We conclude that, in FFR, the increase in COXderived vasodilators associated with the enhancement in endothelium-independent relaxation pathway may constitute compensatory mechanisms for a decreased production of other vasodilators among which NO is the most probable candidate.

In our experimental conditions, an exaggerated pressor response to norepinephrine was found in conscious FFR after 9 weeks of fructose-enriched diet, associated with increased thromboxane $\mathrm{B}_{2}\left(\mathrm{TxB}_{2}\right)$, the stable metabolite of thromboxane $\mathrm{A}_{2}$, urinary levels.

A possible explanation to the heightened contractile response to norepinephrine could be a change in alpha-receptor expression in the vasculature. This specific issue was not addressed in the present work, but this seems to be improbable since in vitro precontraction of aortic rings to phenylephrine was similar in controls and FFR. 
Indomethacin infusion was able to correct the exaggerated response to norepinephrine in FFR. COX dysregulation, which could account for the results on in vitro vascular reactivity, could thus constitute a relevant explanation for in vivo increased pressor response in FFR. Indeed, the enhanced COX-dependent vasoconstrictor $\mathrm{TxB}_{2}$ production is in agreement with Galipeau et al. (2001) showing that fructose overfeeding in rats leads to an increase in $\mathrm{TxB}_{2}$ production. These observations support the concept that $\mathrm{TxB}_{2}$ produced by COX is increased in FFR, therefore leading to an exaggerated pressor response to norepinephrine. This hypothesis was further reinforced by the fact that COX inhibition by indomethacin corrected this abnormal reactivity to stress in FFR. Therefore, despite the absence of elevated baseline blood pressure, FFR showed an exaggerated response to NE that could be associated with COX pathway dysregulation. This support the fact that these FFR are in an early stage of the pathology, showing thus vascular dysfunction rather than a declared hypertensive state, which is already associated with the dysregulation of the COX pathway, leading to production of endothelium-derived constricting factors as previously reported in several models of hypertension including spontaneously hypertensive rats (Lüscher and Vanhoutte 1986), NO-deficient hypertension (Paulis et al. 2008) or aged Wistar-Kyoto rats (Koga et al. 1989). Therefore, this suggests that COX pathway dysregulation may represent a common feature of endothelial dysfunction.

Interestingly, oxidative stress could provide the missing link between insulin resistance/ hypertriglyceridemia and COX dysregulation. Indeed, since NO exhibits an inhibitory effect on COX activity (Kanner et al. 1992), the likely defect of NO in FFR could contribute to COX dysregulation in these animals. Moreover, peroxynitrite was shown to promote preferential $\mathrm{TxA}_{2}$ production by COX (Bachschmid et al. 2005). Thus, one of the consequences of increased oxidative stress in FFR might be the dysregulation of the COX pathway resulting in an increased vasoconstrictor $\mathrm{TxA}_{2}$ production in response to stress, which could explain the exaggerated vasoconstrictor response to norepinephrine.

To conclude, fructose-enriched diet in rats leads to hypertriglyceridemia and insulin resistance. These metabolic abnormalities induced by fructose overload are associated with an enhanced oxidative stress which appears to dysregulate the COX pathway. As a result, in vitro endothelium-dependent relaxations are impaired in the FFR and the in vivo pressor responses to norepinephrine are enhanced. Consequently, oxidative stress markers such as 8-isoprostanes and biomarkers of COX activity such as $\mathrm{TxB}_{2}$ may be good biomarkers of vascular dysfunction associated with the early stages of the metabolic syndrome. The reduction of oxidative stress and the normalization of the COX pathway could constitute new potential therapeutic strategies to limit vascular dysfunction and resulting cardiovascular complications associated with the metabolic syndrome. To conclude the present work gives additional insights about the potential mechanisms linking insulin resistance and endothelial dysfunction.

\section{Conflict of Interest}

There is no conflict of interest.

\section{References}

ANDERSON TJ, UEHATA A, GERHARD MD, MEREDITH IT, KNAB S, DELAGRANGE D, LIEBERMAN EH, GANZ P, CREAGER MA, YEUNG AC: Close relation of endothelial function in the human coronary and peripheral circulations. J Am Coll Cardiol 26: 1235-1241, 1995.

BACHSCHMID M, SCHILDKNECHT S, ULLRICH V: Redox regulation of vascular prostanoid synthesis by the nitric oxide-superoxide system. Biochem Biophys Res Commun 338: 536-542, 2005.

BAKKER SJ, IJZERMAN RG, TEERLINK T, WESTERHOFF HV, GANS RO, HEINE RJ: Cytosolic triglycerides and oxidative stress in central obesity: the missing link between excessive atherosclerosis, endothelial dysfunction, and beta-cell failure? Atherosclerosis 148: 17-21, 2000.

BARON AD: Vascular reactivity. Am J Cardiol 84: 25J-27J, 1999.

BARON AD, CLARK MG: Role of blood flow in the regulation of muscle glucose uptake. Annu Rev Nutr 17: 487-499, 1997.

BARTUS M, LOMNICKA M, LORKOWSKA B, FRANCZYK M, KOSTOGRYS RB, PISULEWSKI PM, CHLOPICKI S: Hypertriglyceridemia but not hypercholesterolemia induces endothelial dysfunction in the rat. Pharmacol Rep 57 (Suppl): 127-137, 2005. 
BEHR-ROUSSEL D, RUPIN A, SIMONET S, FABIANI J, VERBEUREN TJ: Urinary nitrate excretion in cholesterolfed rabbits: effect of a chronic treatment by $\mathrm{N}$-iminoethyl-L-lysine, a selective inhibitor of inducible nitric oxide synthase. Eur J Pharmacol 388: 275-279, 2000.

BEHR-ROUSSEL D, CHAMIOT-CLERC P, BERNABE J, MEVEL K, ALEXANDRE L, SAFAR ME, GIULIANO F: Erectile dysfunction in spontaneously hypertensive rats: pathophysiological mechanisms. Am J Physiol 284: R682-R688, 2003.

BRAY GA, NIELSEN SJ, POPKIN BM: Consumption of high-fructose corn syrup in beverages may play a role in the epidemic of obesity. Am J Clin Nutr 79: 537-543, 2004.

CARANTONI M, ABBASI F, WARMERDAM F, KLEBANOV M, WANG PW, CHEN YD, AZHAR S, REAVEN GM: Relationship between insulin resistance and partially oxidized LDL particles in healthy, nondiabetic volunteers. Arterioscler Thromb Vasc Biol 18: 762-767, 1998.

CATENA C, GIACCHETTI G, NOVELLO M, COLUSSI G, CAVARAPE A, SECHI LA: Cellular mechanisms of insulin resistance in rats with fructose-induced hypertension. Am J Hypertens 16: 973-978, 2003.

COSENTINO F, ETO M, DE PAOLIS P, VAN DER LOO B, BACHSCHMID M, ULLRICH V, KOUROEDOV A, DELLI GATTI C, JOCH H, VOLPE M, LÜSCHER TF: High glucose causes upregulation of cyclooxygenase2 and alters prostanoid profile in human endothelial cells: role of protein kinase $\mathrm{C}$ and reactive oxygen species. Circulation 107: 1017-1023, 2003.

D'ANGELO G, ELMARAKBY AA, POLLOCK DM, STEPP DW: Fructose feeding increases insulin resistance but not blood pressure in Sprague-Dawley rats. Hypertension 46: 806-811, 2005.

DAVIDGE ST: Prostaglandin H synthase and vascular function. Circ Res 89: 650-660, 2001.

DEDON PC, TANNENBAUM SR: Reactive nitrogen species in the chemical biology of inflammation. Archives of Biochemistry and Biophysics 423: 12-22, 2004.

DELBOSC S, PAIZANIS E, MAGOUS R, ARAIZ C, DIMO T, CRISTOL JP, CROS G, AZAY J: Involvement of oxidative stress and NADPH oxidase activation in the development of cardiovascular complications in a model of insulin resistance, the fructose-fed rat. Atherosclerosis 179: 43-49, 2005.

ELLIOTT SS, KEIM NL, STERN JS, TEFF K, HAVEL PJ: Fructose, weight gain, and the insulin resistance syndrome. Am J Clin Nutr 76: 911-922, 2002.

ESPER RJ, NORDABY RA, VILARINO JO, PARAGANO A, CACHARRON JL, MACHADO RA: Endothelial dysfunction: a comprehensive appraisal. Cardiovasc Diabetol 5: 4, 2006.

GALIPEAU D, ARIKAWA E, SEKIROV I, MCNEILL JH: Chronic thromboxane synthase inhibition prevents fructose-induced hypertension. Hypertension 38: 872-876, 2001.

GOPAUL NK, MANRAJ MD, HEBE A, LEE KWAI YS, JOHNSTON A, CARRIER MJ, ANGGARD EE: Oxidative stress could precede endothelial dysfunction and insulin resistance in Indian Mauritians with impaired glucose metabolism. Diabetologia 44: 706-712, 2001.

GRIENDLING KK, ALEXANDER RW: Oxidative stress and cardiovascular disease. Circulation 96: 3264-3265, 1997.

GRUNDY SM: Metabolic syndrome: connecting and reconciling cardiovascular and diabetes worlds. $J$ Am Coll Cardiol 47: 1093-1100, 2006.

HAFFNER SM: Epidemiological studies on the effects of hyperglycemia and improvement of glycemic control on macrovascular events in type 2 diabetes. Diabetes Care 22 (Suppl 3): C54-C56, 1999.

JAFFE M: Über den Niederschlag, welchen Pikrinsäure in normalen Harn erzeugt und über eine neue Reaction des Kreatininis. Z Phys Chem 10: 391-400, 1886.

KAMIDE K, RAKUGI H, HIGAKI J, OKAMURA A, NAGAI M, MORIGUCHI K, OHISHI M, SATOH N, TUCK ML, OGIHARA T: The renin-angiotensin and adrenergic nervous system in cardiac hypertrophy in fructosefed rats. Am J Hypertens 15: 66-71, 2002.

KANNER J, HAREL S, GRANIT R: Nitric oxide, an inhibitor of lipid oxidation by lipoxygenase, cyclooxygenase and hemoglobin. Lipids 27: 46-49, 1992.

KATAKAM PV, UJHELYI MR, HOENIG ME, MILLER AW: Endothelial dysfunction precedes hypertension in dietinduced insulin resistance. Am J Physiol 275: R788-R792, 1998.

KIM JA, MONTAGNANI M, KOH KK, QUON MJ: Reciprocal relationships between insulin resistance and endothelial dysfunction: molecular and pathophysiological mechanisms. Circulation 113: 1888-1904, 2006. 
KOGA T, TAKATA Y, KOBAYASHI K, TAKISHITA S, YAMASHITA Y, FUJISHIMA M: Age and hypertension promote endothelium-dependent contractions to acetylcholine in the aorta of the rat. Hypertension 14: 542-548, 1989.

LEE YC, KO YH, HSU YP, HO LT: Plasma leptin response to oral glucose tolerance and fasting/re-feeding tests in rats with fructose-induced metabolic derangements. Life Sci 78: 1155-1162, 2006.

LÜSCHER TF, VANHOUTTE PM: Endothelium-dependent contractions to acetylcholine in the aorta of the spontaneously hypertensive rat. Hypertension 8: 344-348, 1986.

MATSUDA M, DEFRONZO RA: Insulin sensitivity indices obtained from oral glucose tolerance testing: comparison with the euglycemic insulin clamp. Diabetes Care 22: 1462-1470, 1999.

MEREDITH IT, ANDERSON TJ, UEHATA A, YEUNG AC, SELWYN AP, GANZ P: Role of endothelium in ischemic coronary syndromes. Am J Cardiol 72: 27C-31C, 1993.

MIATELLO R, RISLER N, GONZALEZ S, CASTRO C, RUTTLER M, CRUZADO M: Effects of enalapril on the vascular wall in an experimental model of syndrome X. Am J Hypertens 15: 872-878, 2002.

MIATELLO R, VAZQUEZ M, RENNA N, CRUZADO M, ZUMINO AP, RISLER N: Chronic administration of resveratrol prevents biochemical cardiovascular changes in fructose-fed rats. Am J Hypertens 18: 864-870, 2005.

MONTUSCHI P, BARNES PJ, ROBERTS LJ: Isoprostanes: markers and mediators of oxidative stress. FASEB $J$ 18: 1791-1800, 2004.

NAGAI Y, NISHIO Y, NAKAMURA T, MAEGAWA H, KIKKAWA R, KASHIWAGI A: Amelioration of high fructose-induced metabolic derangements by activation of PPARalpha. Am J Physiol 282: E1180-E1190, 2002.

NAKAGAWA T, HU H, ZHARIKOV S, TUTTLE KR, SHORT RA, GLUSHAKOVA O, OUYANG X, FEIG DI, BLOCK ER, HERRERA-ACOSTA J, PATEL JM, JOHNSON RJ: A causal role for uric acid in fructoseinduced metabolic syndrome. Am J Physiol 290: F625-F631, 2006.

NYBY MD, MATSUMOTO K, YAMAMOTO K, ABEDI K, ESLAMI P, HERNANDEZ G, SMUTKO V, BERGER ME, TUCK ML: Dietary fish oil prevents vascular dysfunction and oxidative stress in hyperinsulinemic rats. Am J Hypertens 18: 213-219, 2005.

PAULIS L, ZICHA J, KUNEŠ J, HOJNÁ S, BEHULIAK M, CELEC P, KOJŠOVÁ S, PECHÁŇOVÁ O, ŠIMKO F: Regression of L-NAME-induced hypertension: the role of nitric oxide and endothelium-derived constricting factor. Hypertens Res 31: 793-803, 2008.

PELAEZ LI, MANRIQUEZ MC, NATH KA, ROMERO JC, JUNCOS LA: Low-dose angiotensin II enhances pressor responses without causing sustained hypertension. Hypertension 42: 798-801, 2003.

REED MJ, HO H, DONNELLY R, REAVEN GM: Salt-sensitive and carbohydrate-sensitive rodent hypertension: evidence of strain differences. Blood Press 3: 197-201, 1994.

RUIZ FJ, SALOM MG, INGLES AC, QUESADA T, VICENTE E, CARBONELL LF: N-acetyl-L-cysteine potentiates depressor response to captopril and enalaprilat in SHRs. Am J Physiol 267: R767-R772, 1994.

SANCHEZ-LOZADA LG, TAPIA E, JIMENEZ A, BAUTISTA P, CRISTOBAL M, NEPOMUCENO T, SOTO V, AVILA-CASADO C, NAKAGAWA T, JOHNSON RJ, HERRERA-ACOSTA J, FRANCO M: Fructoseinduced metabolic syndrome is associated with glomerular hypertension and renal microvascular damage in rats. Am J Physiol 292: F423-F429, 2007.

SHINOZAKI K, SUZUKI M, IKEBUCHI M, TAKAKI H, HARA Y, TSUSHIMA M, HARANO Y: Insulin resistance associated with compensatory hyperinsulinemia as an independent risk factor for vasospastic angina. Circulation 92: 1749-1757, 1995.

SHINOZAKI K, KASHIWAGI A, NISHIO Y, OKAMURA T, YOSHIDA Y, MASADA M, TODA N, KIKKAWA R: Abnormal biopterin metabolism is a major cause of impaired endothelium-dependent relaxation through nitric oxide $/ \mathrm{O}_{2}{ }^{-}$imbalance in insulin-resistant rat aorta. Diabetes 48: 2437-2445, 1999.

SHINOZAKI K, NISHIO Y, OKAMURA T, YOSHIDA Y, MAEGAWA H, KOJIMA H, MASADA M, TODA N, KIKKAWA R, KASHIWAGI A: Oral administration of tetrahydrobiopterin prevents endothelial dysfunction and vascular oxidative stress in the aortas of insulin-resistant rats. Circ Res 87: 566-573, 2000.

SONG D, ARIKAWA E, GALIPEAU D, BATTELL M, MCNEILL JH: Androgens are necessary for the development of fructose-induced hypertension. Hypertension 43: 667-672, 2004. 
SONNENBERG GE, KRAKOWER GR, KISSEBAH AH: A novel pathway to the manifestations of metabolic syndrome. Obes Res 12: 180-186, 2004.

TAKADA M, URA N, HIGASHIURA K, MURAKAMI H, TOGASHI N, SHIMAMOTO K: Effects of cilnidipine on muscle fiber composition, capillary density and muscle blood flow in fructose-fed rats. Hypertens Res 24: 565 572, 2001.

TAKAGAWA Y, BERGER ME, TUCK ML, GOLUB MS: Impaired endothelial alpha-2 adrenergic receptor-mediated vascular relaxation in the fructose-fed rat. Hypertens Res 25: 197-202, 2002.

VASUDEVAN H, XIANG H, MCNEILL JH: Differential regulation of insulin resistance and hypertension by sex hormones in fructose-fed male rats. Am J Physiol 289: H1335-H1342, 2005. 